\title{
Advances in Clinical Toxicology
}

\section{Glucose Transporter 4, Biomarker Development and Metabolic Syndrome in the Arctic}

\author{
Dunlap $K^{1,2}$, Schnurr TM³ , Sticka $K^{4}$, Vertigan $\mathrm{T}^{1}$ and Duffy $\mathrm{LK}^{1,2 *}$ \\ 1Department of Chemistry and Biochemistry, University of Alaska Fairbanks, USA \\ 2Institute of Arctic Biology, University of Alaska Fairbanks, USA \\ ${ }^{3}$ Novo Nordisk Research Foundation Center for Basic Metabolic Research, University \\ of Copenhagen, Denmark \\ ${ }^{4}$ Culinary Arts, Hospitality, Dietetics and Nutrition Division, University of Alaska Anchorage, USA
}

\begin{tabular}{|c|}
\hline Commentary \\
Volume 2 Issue 2 \\
Received Date: November 08,2017 \\
Published Date: December 07,2017 \\
\hline
\end{tabular}

*Corresponding author: Lawrence K Duffy, Department of Chemistry and Biochemistry, University of Alaska Fairbanks, AK 99775-6160, USA, Tel: 907-474-7525; E-mail: lkduffy@alaska.edu

\section{Abstract}

A general hindrance to research and clinical surveillance in the Arctic and sub-Arctic is the lack of early measured, supporting biomarkers for risk assessment. The increasing prevalence of visceral obesity is a risk factor for metabolic syndrome and has been associated with an increased risk for type-2 diabetes. Environmental chemical pollutant exposure can have an impact on adipose tissue function.

The common sources of exposure for metals in the Arctic are air, water and food. Metals have been reported to affect behavior of adipocytes; methyl mercury has been shown to be cytotoxic to differentiating adipocytes. This impact on differentiation suggests that GLUT-4 as a biomarker for the impairment of the insulin-signaling pathway would be a valuable tool for studying type-2 diabetes and metabolic syndrome. The Glucose transporter 4 (GLUT-4) is a widely studied biomarker in myocytes, adipocytes and more recently peripheral blood mononuclear cells (PBMC). PBMC GLUT-4 may be a good molecule for studying the impacts of mercury in different sentinel species residing in the North. GLUT - 4 has been studied in both canines and humans and samples from both species can be obtained from rural Arctic communities.

Keywords: Metabolic Syndrome; Adipocytes; Arctic; Biomarkers; Glucose

Abbreviations: T2D: Type 2 Diabetes; Met S: Metabolic Syndrome; PBMC: Peripheral Blood Mononuclear Cells; GLUT-4: Glucose Transporter 4

\section{Introduction}

Tens of thousands of industrial and personal product chemicals are in use today and distributed globally, often 


\section{Advances in Clinical Toxicology}

ending up in the Arctic. Many of these chemicals, such as mercury, have potential health risks to humans and other organisms in the environment [1-3]. Lead, mercury and cadmium are commonly used metals that have led to widespread contamination of food and water $[3,4]$. There is currently a scarcity of information regarding the effects of exposure to these metals on cytokine regulation when released by adipocytes as it pertains to the related syndromes of obesity and type 2 diabetes (T2D) $[5,6]$.

Glucose homeostasis is related to insulin signaling and Glucose Transporter-4 (GLUT-4). GLUT-4 resides on small intracellular vesicles that are translocated to the plasma membrane in response to insulin and facilitate the uptake of glucose [7]. The ability to track GLUT-4 is essential to understanding whole body glucose homeostasis. GLUT-4 trafficking represents a potential early defect and contributes to insulin resistance in diabetes [8]. Studies in both humans and dogs, have demonstrated the presence of white blood cells containing GLUT-4 which suggests that measurement of GLUT-4 levels in peripheral blood mononuclear cells (PMBC) has the potential to be used as a biomarker for insulin resistance [9-12].

This creates the possibility of correlating plasma metal or persistent organic pollutants (POPs) exposure to the PBMC GLUT-4 levels, and developing a quantitative risk exposure model for T2D and Metabolic syndrome (Met S) in rural and extreme environments.

\section{Traditional Lifestyle}

Over the past 100 years, societies in the North American Arctic and sub-Arctic have transitioned toward the "Western diet", composed primarily of highly processed 'factory foods' high in sugars, omega- 6 and saturated fatty acids, and low in fiber, phytoactive compounds from fruits, and omega-3 fatty acids. This 'nutrition transition' has been identified as playing a central role in the significant development of obesity, insulin resistance, and metabolic syndrome, which in turn are major risk factors for cardiovascular disease and T2D [13-15].

The American Diabetes Association lists American Indians and Alaska Natives as one of the highest risk populations for developing T2D, with a prevalence of $16 \%$ compared with a $9 \%$ national average [16]. However, research that focuses solely on isolated Alaska Native communities, that preserve traditional diets, report lower rates of diabetes, even though obesity rates in these populations equal or exceed the national average. Geographic isolation in Alaska and the Arctic has retained the hunter gatherer lifestyle. Alaska Natives rely on traditional diets and have a historically low prevalence of diet-related diseases [17]. The relatively low rates of diabetes among Alaska Natives are attributed to diets high in fish and berries, along with the active lifestyle that accompanies hunting and gathering of traditional foods [18]. Alaskan villagers eat on average $4.8 \mathrm{~kg}$ of subsistence foods per week, $60 \%$ of which are finfish such as salmon [19-21]. The traditional Alaska Native diet is higher in omega-3 fatty acids than the diet of the general US population. Many types of berries are also common in Alaska and have been shown to have positive health effects, including anti-diabetic and anti-inflammatory properties [20,22]. Seasonal harvests are major community events especially in rural Alaska communities. People commonly harvest berries of the Vaccinium genus (bog blueberries, lowbush cranberries, and other wild berries), when the berries are ripe in July, August and September, and use them year-round both for food and medicine $[22,23]$. Climate change and global transport of contaminants may place the quality of subsistence food at risk in the future $[23,24]$.

\section{Dog Model}

Dogs are an ideal research model for immune function, nutrition, exercise, toxicology and aging [12]. Because they possess key features associated with cognitive dysfunctions such as beta-amyloid pathology and oxidative damage, similar to that of humans, dogs are also a good model for the study of aging $[11,25,26]$. Dog mushing, once used primarily as a means of transportation in the North, has evolved into a popular national and international sport. Not only do dogs connect to people but this lends to diversity in climate, diet and location, providing great research opportunities. Dogs in northern climates are often exposed to the same environmental hazards as their human counterparts $[25,27]$. In many Alaskan villages, sled dogs are still a fundamental part of a traditional lifestyle, used for trapping, packing and transportation. Most of these communities are small settlements, established on or near rivers to facilitate travel and to gather food. Like humans, the dogs' diet in Alaska and the Arctic is often comprised of a variety of wild game and fish [24]. High Hg levels have been found in dogs, but unlike humans $\mathrm{Hg}$ levels in dogs have not yet been correlated with metabolic phenotypes [28-30].

Though there are species-specific pathologies associated with diabetes, dogs develop insulin dependent and independent forms of diabetes [28]. The prevalence of canine diabetes (classified into insulin deficiency 


\section{Advances in Clinical Toxicology}

diabetes group) is significantly lower than human, which could be a result of better diagnostics in humans or an increased incidence of risk factors like obesity, for humans, or both. Dogs are a proven model for biochemical research and can be an innovative model to link activity and nutrition to the physiological and immune effects seen in metabolic syndrome and related disorders [12]. Also, for the circumpolar north, racing sled dogs are excellent models for studying the impacts exercise and nutrition have on metabolic syndrome.

\section{Metabolic Syndrome (Met S)}

Obesity has become a major worldwide public health issue and has been characteristically linked with hypertension and inflammation as risk factors for Metabolic Syndrome (Met S), a group of several medical conditions associated with developing the risks of type 2 diabetes and insulin resistance [30,32,33]. DeLong and Holloway have suggested that environmental exposure to synthetic chemicals, especially early life exposure to heavy metals, flame retardants and pesticides [28,30,31], may have a role in metabolic syndrome's recent increase. However, there is little published information regarding the effects of prenatal or early childhood exposure to metals and adult glucose homeostasis [34]. While the correlation between $\mathrm{Hg}$ and PBMC GLUT-4 has not yet been explored, increased Hg levels have been correlated with lower anti-oxidant levels and higher TNF (unpublished) and leukotrienes B4 [29]. If, as proposed, Met $S$ risk increases with early life exposure to contaminants, it would be worthwhile to use GLUT-4 to examine the connection between exposure and glucose homeostasis

\section{GLUT-4 as a Biomarker}

Biomonitoring uses biomarkers of exposure such as metal or organic pollutant, or biomarkers of effect such as the induction of an enzyme or the movement of a transport protein. Biomonitoring the effects of a stress, such as environmental exposure, provides trend data which can be used to develop optional health advice regarding food consumption and lifestyle factors. A good biomarker can detect both spatial and temporal trends.

GLUT-4 plays a key role in the pathophysiology of T2D and is up regulated in response to exercise which enhances cellular glucose transport in skeletal muscle tissue [8,9,11]. Maratou and colleagues have demonstrated the presence of GLUT-4 in white blood cells (PBMC). This mechanism appears to remain intact in individuals with insulin resistance [10,33]. Details of the mechanism are poorly understood and are challenging to study due to the invasive nature of muscle biopsy. Peripheral blood mononuclear cells (PBMC) have documented insulin-sensitive GLUT-4 activity and may serve as a proxy tissue for studying skeletal muscle GLUT4 [35]. Recent studies indicate higher PBMC GLUT-4 levels in conditioned dogs and human athletes [11,12,35,36]. Differences in GLUT-4 levels use an easily accessible blood cell protein. The measurement of GLUT-4 provides a new biomarker for future studies with environmental stressors such as metal and pollutants.

\section{Conclusion}

This commentary suggests the exploration of GLUT-4 from PBMC as a proxy tissue for studying GLUT-4 response to chemical stressors in individuals at risk for Met S. When concurrent monitoring of increased contaminant levels is available, a risk assessment model can be developed.

\section{Acknowledgements}

This work is the responsibility of the authors and does not necessarily represent the official view of the University of Alaska or any previous funding sources. We appreciate the stimulating discussions with the following colleagues: Arleigh Reynolds, Scott Jerome, Sven Ebbesson and Mary van Muelken.

\section{References}

1. Duffy LK (2014) Arctic Air Pollution in Antarctica and the Arctic Circle, Hund AJ (Ed.), ABC-CLIO, Santa Barbara, CA, pp: 55-57.

2. Duffy LK, Vertigan T, Dainowski B, Hirons AC (2017) Climate Change, One Health and Mercury. Adv Clin Toxicol 2(1): 000114.

3. AMAP (2011) Arctic Pollution 2011. Arctic Monitoring and Assessment Program, Oslo, pp: 38.

4. Sharp D (2009) Environmental toxins, a potential risk factor for diabetes among Canadian Aboriginals, International Journal of Circumpolar Health, 68(4): 316-325.

5. Lara-Castro C, Fu Y, Chung BH, Garvey W T (2007) Adiponectin and the metabolic syndrome: Mechanisms mediating risk for metabolic and 


\section{Advances in Clinical Toxicology}

cardiovascular disease. Current Opinion in Lipidology 18(3): 263-270.

6. Renaldi O, Pramono B, Sinorita H, Purnomo LB, Asdie $\mathrm{RH}$, et al. (2009) Hypoadiponectinemia: a risk factor for metabolic syndrome. Acta Medica Indonesiana 1(1): 20-24.

7. Hussey SE, McGee SL, Garnham A, McConell GK, Hargreaves M (2012) Exercise increases skeletal muscle GLUT4 gene expression in patients with type 2 diabetes. Diabetes Obesity and Metabolism 14(8): 768-771.

8. Richter EA, Hargreaves M (2013) Exercise, GLUT4, and Skeletal Muscle Glucose Uptake. Physiol Rev 93(3): 993-1017.

9. Maratou E, Dimitriadis G, Kollias A, Boutati E, Lambadiari V, et al. (2007) Glucose transporter expression on the plasma membrane of resting and activated white blood cells. European Journal of Clinical Investigation 37(4): 282-290.

10. Maratou, E, Hadjidakis, DJ, Kollias, A, Tsegka, K Peppa, M, Alevizaki, M et al. (2009) Studies of insulin resistance in patients with clinical and subclinical hypothyroidism. Eur J Endocrinol 160(5): 785-790.

11. Schnurr T, Reynolds A, Gustafson S, Duffy L, Dunlap K (2014) Conditioning causes an increase in Glucose Transporter-4 levels in mononuclear cells in sled dogs. Int J Biochem Cell Biol 55: 227-231.

12. Schnurr TM, Reynolds AJ, Duffy LK, Dunlap KL (2014) Glucose Transporter 4 expressions in white blood cells of young and old sled dogs : a model for human biomarker development. Polar Record 51(2):160164.

13. O'Keefe JH, Vogel R, Lavie CJ, Cordain L (2010) Achieving Hunter-gatherer Fitness in the 21st Century: Back to the Future. The American Journal of Medicine 123(12): 1082-1086.

14. Cordain L, Eaton SB, Sebastian A, Mann N, Lindeberg $S$, et al. (2005) Origins and evolution of the Western diet: health implications for the 21st century. Am J Clin Nutr 81(2): 341-354.

15. Ramsden CE, Faurot KR, Carrera-Bastos P, Cordain L, De Lorgeril, et al. (2009) Dietary fat quality and coronary heart disease prevention: A unified theory based on evolutionary, historical, global, and modern perspectives. Current Treatment Options in Cardiovascular Medicine 11(4): 289-301.

16. American Diabetes Association (2014) Treatment and Care for American Indians/Alaska Natives. Accessed November 6, 2017.

17. Loring PA, Gerlach SC (2009) Food, culture, and human health in Alaska: An integrative health approach to food security. Environmental Science \& Policy 12: 466-478.

18. Johnson JS, Nobmann ED, Asay E, Lanier AP (2009) Dietary intake of Alaska Native people in two regions and implications for health: the Alaska Native Dietary and Subsistence Food Assessment Project. International Journal of Circumpolar Health 68(2):109-122.

19. Jewett SC, Duffy LK (2007) Mercury in fishes of Alaska, with emphasis on subsistence species. Sci Total Environ 387(1-3): 3-27.

20. Ebbesson SOE, Tejero ME, López-Alvarenga JC, Harris WS, Ebbesson LOE, et al. (2010) Individual saturated fatty acids are associated with different components of insulin resistance and glucose metabolism: the GOCADAN study. International Journal of Circumpolar Health 69(4): 344-351.

21. Thorseng TW, Dorte DV, Borch-Johnsen K, Bjerregaard P, Jørgensen M (2009) The association between $n-3$ fatty acids in erythrocyte membranes and insulin resistance: The Inuit Health in Transition Study. International journal of circumpolar health 68(4): 327-336.

22. Grace MH, Esposito D, Dunlap KL, Lila MA (2014) Comparative Analysis of Phenolic Content and Profile, Antioxidant Capacity, and Anti-inflammatory Bioactivity in Wild Alaskan and Commercial Vaccinium Berries. Journal of Agricultural and Food Chemistry 62(18): 4007-4017.

23. Kellogg J, Wang J, Flint C, Ribnicky D, Kuhn P, et al. (2010) Alaskan Wild Berry Resources and Human Health under the Cloud of Climate Change. Journal of Agricultural and Food Chemistry 58(7): 3884-3900.

24. Dunlap KL, Reynolds AJ, Duffy LK, Gerlach SG, Loring PA, et al. (2011) Selected plasma fatty acid levels in subsistence fed sled dogs along the Yukon River: a pilot study for biomonitoring. Polar Record 48(2): 177-183. 
25. Harley JR, Bammler TK, Farin FM, Beyer RP, Kavanagh TJ, et al. (2016) Using Domestic and FreeRanging Arctic Canid Models for Environmental Molecular Toxicology Research. Environmental Science \& Technology 50(4): 1990-1999.

26. Alves JC, Santos A (2016) Physiological, haematological and biochemical shifts in police working dogs during a riot control exercise. Comparative Exercise Physiology 12(4): 193-198.

27. Duffy LK, Dunlap KL, Reynolds A, Gerlach SC (2013) Sled dogs as indicators of climate change and resultant contaminant fate and transport along the Yukon River. Int J Circumpolar Health Supplements 72: 508-510.

28. De Long NE, Holloway AC (2017) Early-life chemical exposures and risk of metabolic syndrome. Diabetes, Metabolic Syndrome and Obesity: Targets and Therapy 10: 101-109.

29. Dunlap KL Reynolds AJ, Gerlach SC, Duffy LK (2011) Mercury interferes with endogenous antioxidant level in Yukon River subsistence-fed sled dogs. Environ Res Lett 6(4): 1-5.

30. Lee K (2017) Blood mercury concentration in relation to metabolic and weight phenotypes using the KNHANES 2011-2013 data. Int Arch Occup Environ Health 1-9.

\section{Advances in Clinical Toxicology}

31. Weixiang Wu, Shunli Jiang, Qiang Zhao, Ke Zhang, Xiaoyun Wei, et al. (2017) Environmental exposure to metals and the risk of hypertension: A cross-sectional study in China, Environ Pollut 233: 670-678.

32. Smith U, Kahn BB (2016) Adipose tissue regulates insulin sensitivity: role of adipogenesis, de novo lipogenesis and novel lipids. J Intern Med 280(5): 465-475.

33. Monteiro R, Azevedo I (2010) Chronic Inflammation in Obesity and the Metabolic Syndrome. Mediators of Inflammation 2010(2010): 1-10.

34. Faulk C, Barks A, Sánchez BN, Zhang Z, Anderson OS, et al. (2014) Perinatal Lead (Pb) Exposure Results in Sex-Specific Effects on Food Intake, Fat, Weight, and Insulin Response across the Murine Life-Course. PLoS ONE 9(8): e104273.

35. Sticka, Kendra (2016) Glucose Transporter-4 On Peripheral Blood Mononuclear Cells in Conditioned Vs. Sedentary College Students, University of Alaska Fairbanks PhD thesis.

36. Goodyear LJ, Kahn BB (1998) Exercise glucose transport and insulin sensitivity. Annu Rev Med 49: 235-261. 